\title{
Variations
}

Variations

Revue internationale de théorie critique

18 | 2013

"La poésie est une arme chargée de futur »

\section{Stéphane Haber, Freud et la théorie sociale}

\section{Alexander Neumann}

\section{(2) OpenEdition}

Journals

Édition électronique

URL : http://journals.openedition.org/variations/654

DOI : 10.4000/variations.654

ISSN : 1968-3960

\section{Éditeur}

Les amis de Variations

\section{Référence électronique}

Alexander Neumann, « Stéphane Haber, Freud et la théorie sociale », Variations [En ligne], 18| 2013, mis en ligne le 31 mai 2013, consulté le 22 septembre 2020. URL : http://journals.openedition.org/ variations/654; DOI : https://doi.org/10.4000/variations.654

Ce document a été généré automatiquement le 22 septembre 2020

Les ami•e•s de Variations 


\title{
Stéphane Haber, Freud et la théorie sociale
}

\author{
Alexander Neumann
}

\section{RÉFÉRENCE}

Stéphane Haber, Freud et la théorie sociale, La Dispute, 2012, 278 pages

1 Certains des titres du fondateur de la psychanalyse font aujourd'hui l'actualité, Le malaise dans la civilisation en tête. Stéphane Haber saisit pleinement cette étrange présence. L'ouvrage cherche à dépasser un dilemme nodal des sciences humaines dans le monde occidental : l'opposition théorique catégorielle et caricaturale entre l'individu et le social. Le point de départ de l'argumentation est éminemment critique, car la «division intuitive» entre le social et l'individuel ne résiste pas à un examen approfondi, qui s'expose ici en trois temps, afin d'arriver à relancer Freud au sein d'une théorie sociale contemporaine.

2 Les trois grandes parties qui composent le livre discutent le triptyque qui organise l'univers conceptuel de Freud et de sa postérité intellectuelle : le ça, le moi, le sur-moi. Habituellement, les trois termes sont associés à la pulsion, à la personnalité et à l'autorité, alors que Stéphane Haber pointe aussi bien la fertilité que l'approximation théorique des définitions introduites par Freud. Le déploiement discursif du livre s'inspire du développement successif de la pensée freudienne, qui part du livre Le ça et le moi. Dans cette première interprétation que propose Freud, le ça n'est pas encore cerné dans toute sa profondeur, tandis que le sur-moi n'apparaît pas dans le titre. La suite du débat théorique est une longue histoire de prises, reprises et tentatives d'appropriation, que Stéphane Haber retrace de manière précise et convaincante.

3 La proposition d'Haber se distingue par une beauté conceptuelle certaine, puisqu'elle arrive à saisir, sans les banaliser, les ramifications, paradoxes et querelles autour de Freud qui traversent plusieurs décennies et disciplines à travers trois mots, ça, moi, sur-moi. Preuve de l'importance de l'héritage freudien qui permet la formation des 
personnalités en société, au milieu et malgré une mondialisation qui affirme son caractère totalisant et coercitif. Le ça et le moi forment en quelque sorte les piliers porteurs à partir desquels la voûte des représentations sociales globales peuvent se penser. En cela, la pureté conceptuelle fait penser aux principes de l'architecture gothique exposés par Panofsky. Nous sommes très loin des approximations superficielles auxquelles se livrent les rédacteurs de livres noirs de la psychanalyse, ou encore des certitudes d'une sociologie positiviste qui rejette les effets "psychologisants» d'explications qui sortent du schéma statistique de "l'homme moyen ».

4 La vue d'ensemble présente une succession d'approches critiques du triptyque freudien initial (connu sous l'appellation de "seconde topique »), où Laplanche est discuté en relation avec le langage théorique du ça, Lacan en lien avec le moi, et Adorno en rapport avec le sur-moi, entre autres auteurs classiques. Laplanche traque le naturalisme débordant de la théorie des pulsions, ce qui fait qu'il gagne en précision analytique mais au prix d'une épuration qui réduit in fine le champ clinique et conceptuel, dont la polyphonie du langage corporel.

5 La discussion centrée sur le moi pose, ensuite, la question de savoir comment cerner l'idée de l'objet du désir. Haber s'interroge, à travers Lacan, sur la possibilité d'une définition non positiviste de cet objet, qui semble pensable à partir de la distinction entre besoin naturel et désir humain. L'idée que la quête d'une satisfaction passe donc toujours par des voies détournées (envie, reconnaissance, etc.) succombe cependant à une "surenchère" intellectuelle qui fait que le désir d'autre chose se réduit finalement au désir de l'Autre, où l'objet détourné du désir n'existe plus.

6 Parmi les auteurs explorés en lien avec le sur-moi, Haber signale l'ambivalence d'Adorno face à la définition freudienne. D'un côté, Les études sur la personnalité autoritaire, désormais accessibles en langue française, décrivent le sur-moi de manière assez classique comme l'intériorisation de l'autorité sociale et morale, mais de l'autre, Adorno semble associer la perte ou le basculement de ce sur-moi traditionnel à l'affirmation du fascisme européen. Au final se dessine une fausse alternative: autoritarisme traditionnel ou fascisme. Haber se tourne alors vers Axel Honneth, philosophe francfortois qui s'affiche en rupture avec Adorno, pour approcher une philosophie sociale tournée vers l'expérience individuelle. À notre avis, cette approche s'exprime déjà chez Adorno dans Minima moralia. Réflexions sur la vie mutilée, mais cela renvoie à une vaste discussion sur le développement de la Théorie critique qui dépasse le sujet de notre recension.

7 Stéphane Haber réussit à nommer, à problématiser et à rendre parlantes des questions freudiennes initiales qui ont fait l'objet d'innombrables débats qu'il restitue fidèlement dans le but de les projeter vers l'avenir. En cela il effectue une percée libératrice qui contredit à elle seule la prétendue fatalité de la mondialisation totalisante, qui menace d'étouffer toute pensée émancipatrice par l'angoisse et l'inhibition. Désinhiber la théorie sociale et les intellectuels qui la pratiquent, tel est l'un des objectifs du livre, face au réalisme apparent du fait accompli. 